\title{
Developmental competence in vivo and in vitro of in vitro- matured equine oocytes fertilized by intracytoplasmic sperm injection with fresh or frozen-thawed spermatozoa
}

\author{
Y. H. Choi ${ }^{1}$, C. C. Love ${ }^{1}$, L. B. Love ${ }^{1}$, D. D. Varner ${ }^{2}$, \\ S. Brinsko ${ }^{2}$ and K. Hinrichs ${ }^{*}$ \\ ${ }^{1}$ Departments of Veterinary Physiology and Pharmacology and ${ }^{2}$ Large Animal Medicine and \\ Surgery, College of Veterinary Medicine, Texas A\&M University, College Station, \\ TX 77843-4466, USA
}

This study was undertaken to evaluate the development of equine oocytes in vitro and in vivo after intracytoplasmic sperm injection (ICSI) with either fresh or frozen-thawed spermatozoa, without the use of additional activation treatments. Oocytes were collected from ovaries obtained from an abattoir and oocytes classified as having expanded cumulus cells were matured in M199 with $10 \%$ fetal bovine serum and $5 \mu \mathrm{U} \mathrm{FSH} \mathrm{ml-1}$. After 24-26 h of in vitro maturation, oocytes with a first polar body were selected for manipulation. Fresh ejaculated stallion spermatozoa were used for the experiment after swim-up for $20 \mathrm{~min}$ in sperm-Tyrode's albumen lactate pyruvate. Frozen-thawed spermatozoa from the same stallion were treated in a similar way. Spermatozoa were immobilized and injected into the oocytes using a Piezo drill. Presumptive zygotes were cultured in G1.2 medium for 20 or $96 \mathrm{~h}$ after the injection was administered, or were transferred to the oviducts of recipient mares and recovered $96 \mathrm{~h}$ later. In addition, bovine oocytes with first polar bodies were injected with the two types of stallion spermatozoa and fixed $20 \mathrm{~h}$ after injection to examine pronuclear formation. Fertilization rate (pronucleus formation and cleavage) at $20 \mathrm{~h}$ after injection of spermatozoa was not significantly different between fresh and frozen-thawed sperm groups in either equine or bovine oocytes. Pronucleus formation after injection of spermatozoa into bovine oocytes was significantly higher than that for equine oocytes $(P<0.05)$. There were no significant differences in cleavage rate or average number of nuclei at $96 \mathrm{~h}$ between equine oocytes injected with fresh or frozen-thawed spermatozoa. However, embryos developed in vivo for $96 \mathrm{~h}$ had a significantly higher number of nuclei in both sperm treatments compared with those cultured in vitro. These results indicate that good activation rates may be obtained after injection of either fresh or frozen-thawed equine spermatozoa without additional activation treatment. Injection of frozen-thawed equine spermatozoa results in similar embryo development to that obtained with fresh equine spermatozoa. In vitro culture of equine zygotes in G1.2 medium results in a similar cleavage rate but reduced number of cells compared with in vivo culture within the oviduct. Bovine oocytes may be useful as models for assessing sperm function in horses.

\section{Introduction}

Over the last decade, only low rates of fertilization have been achieved after conventional IVF in horses (Bezard et al., 1989; Dell'Aquila et al., 1999). This low rate of fertilization appears to be related to the inability of spermatozoa to penetrate the equine zona pellucida in vitro, as fertilization rates are greatly improved by partial removal or by drilling of the zona pellucida (Choi et al., 1994; Li et al., 1995). Only two foals have been produced by conventional IVF, both resulting from insemination of an oocyte matured in vivo (Palmer et al., 1991; Bezard et al., 1992). Intra-

*Correspondence

Email: khinrichs@cvm.tamu.edu cytoplasmic sperm injection (ICSI) has been used in horses (Squires et al., 1996; Grondahl et al., 1997; Dell'Aquila et al., 1997a,b, 1999; Cochran et al., 1998; Li et al., 2000) because it bypasses critical fertilization events, such as the acrosome reaction, zona pellucida binding and penetration, and sperm-egg membrane fusion.

The percentage of male pronucleus formation in oocytes after ICSI in horses varies from 21 to $68 \%$ (Dell'Aquilla et al., 1997a; Grondahl et al., 1997; Guignot et al., 1998; Li et al., 2000). Cleavage rates after ICSI of equine oocytes have typically been reported without fixation or staining, and thus the actual proportion of embryos with normal development is not clear. Reported cleavage rates range from 20 to 65\% (Dell'Aquila et al., 1997b; Grondahl et al., 1997; Kato et al., 1997; Cochran et al., 1998; Guignot et al., 1998; McKinnon et al., 2000; Schmid et al., 2000; Li et al., 2001). 
Three different preparations of equine spermatozoa have been used for ICSI: fresh (Kato et al., 1997; Schmid et al., 2000), cooled (Cochran et al., 1998; Li et al., 2000) and frozen-thawed (Grondahl et al., 1997; Dell'Aquila et al., 1997a,b, 1999; Li et al., 2001). There appears to be controversy over the necessity for activation treatment after ICSI in horses. Researchers working with fresh semen achieved minimal pronucleus formation unless oocytes were chemically activated after ICSI (Kato et al., 1997; Guignot et al., 1998; Schmid et al., 2000). Use of cooled semen either required ( $\mathrm{Li}$ et al., 2000) or did not require (Cochran et al., 1998) chemical activation for pronucleus formation. Groups using frozen-thawed spermatozoa have reported good rates of pronucleus formation (about 50\%) without activation treatment after ICSI (Grondahl et al., 1997; Dell'Aquilla et al., 1997a,b, 1999; McKinnon et al., 2000), although some workers have combined the use of frozen-thawed spermatozoa with activation treatment ( $\mathrm{Li}$ et al., 2001).

Spermatozoa injected into the oocyte by ICSI are still enveloped by their plasma membrane, but must be capable of releasing the factors involved in oocyte activation. In conventional ICSI, spermatozoa are treated by pressing the tail of the spermatozoa against the bottom of a dish to immobilize it and damage the sperm plasma membrane to facilitate release of sperm-borne oocyte-activation factors (Dozortsev et al., 1995). It is possible that the process of freezing spermatozoa results in changes to the sperm membrane that allow more rapid or more complete diffusion of sperm factors into the cytoplasm of the oocyte. Therefore, the differences in reported requirements for chemical activation after ICSI in horses may be related to the type of spermatozoa used.

It has been suggested that the sperm-borne oocyteactivation factor is both soluble (Swan, 1990), and is released after repeated freezing and thawing in liquid nitrogen, and insoluble (Perry et al., 1999), that is, present in the membrane. The sperm-borne oocyte-activation factor is not species-specific: pig cytosolic sperm factor can activate mouse and bovine oocytes (Fissore et al., 1998; Perry et al., 1999). In addition, spermatozoa from species, such as hamsters, rats, rabbits, humans or sea urchins can activate mouse oocytes (Rybouchikin et al., 1995; Wakayama et al., 1997; Yazawa et al., 2000). In other reports, interspecies fertilization after ICSI has been reported in conjunction with additional activation treatments. Injection of bovine, mouse or human spermatozoa, combined with electrical stimulus, resulted in activation of pig oocytes (Kim et al., 1999), and injected killed ovine, bovine or minke whale spermatozoa activated bovine oocytes when combined with ethanol treatment (Wei and Fukui, 2000). However, there are no reports available on the capacity of spermatozoa of different species to activate bovine oocytes without additional activation stimulation. Bovine oocytes have been used as a model for zona-free penetration assay using equine spermatozoa (Choi et al., 1999a; Landim-Alvarenga, 2001). Bovine oocytes have also been used as host cytoplast for nuclei from other species (Dominko et al., 1999), including horses (Hinrichs et al., 2000).

In vitro culture systems have not been developed to support equine embryonic development, and few studies have been carried out in this area. This lack of research is due, in part, to the small number of equine embryos available for investigation, as equine oocytes are difficult to recover in large numbers (Hinrichs, 1998). In vitro culture of ICSI-derived embryos for only $26-28 \mathrm{~h}$ reduced the pregnancy rate after oviductal transfer compared with those embryos transferred earlier (4-8 h) after ICSI (McKinnon et al., 2000). In vivo-derived one- to two-cell equine embryos did not produce blastocysts unless co-cultured with uterine tubal epithelial cells (Ball et al., 1993). In co-culture, 35\% of embryos developed to blastocysts. Because of inadequate in vitro embryo culture systems, few reports are available on the development of ICSI embryos in vitro. Three laboratories have produced blastocysts from ICSI-embryos in culture in vitro, but in small to moderate proportions (1 of 79, Dell'Aquila et al., 1997b; 1 of 76, Guignot et al., 1998; 10 of 33, Li et al., 2001). Pregnancies and foals have resulted from the transfer of ICSI-produced zygotes and embryos to the oviducts of recipient mares, but again, in small proportions (Squires et al., 1996; Cochran et al., 1998; McKinnon et al., 2000). Transfer of ICSI blastocysts produced in vitro to the uterus with the subsequent birth of live foals, has been reported by Li et al. (2001). There is no information available comparing development of ICSI embryos in the oviduct in vivo to that achieved in vitro.

In this study, the activation rate of oocytes fertilized by ICSI was investigated using fresh or frozen-thawed equine spermatozoa, and their subsequent development both in vivo, after transfer to the oviducts of recipient mares, and in vitro was evaluated. In addition, the activation rate of the two types of spermatozoa was evaluated when injected into bovine oocytes to determine whether bovine oocytes are a suitable model for equine oocytes.

\section{Materials and Methods}

\section{Oocyte collection}

Ovaries were transported from the abattoir to the laboratory at room temperature (3-4 h transport time). Adnexa were trimmed from the ovaries with scissors and the ovaries were cleaned with sterilized gauze. All visible follicles were opened with a scalpel blade and the granulosa layer of each follicle was scraped using a $0.5 \mathrm{~cm}$ bone curette. The contents of the curette were washed into individual Petri dishes with Hepes-buffered TCM-199 with Hank's salts (Gibco Life Technologies, Inc, Grand Island, $\mathrm{NY})$ plus ticarcillin $(0.1 \mathrm{mg} \mathrm{ml}-1$, SmithKline Beecham Pharmaceuticals, Philadelphia, PA). The contents of the Petri dishes were examined under a dissection microscope at $\times 10-20$ magnification. Cumulus-oocyte complexes were classified as compact, expanded or degenerating depending 
on the expansion of both mural granulosa and cumulus as described previously (Hinrichs and Williams, 1997; Hinrichs and Schmidt, 2000). Oocytes with any sign of expansion of either the cumulus or the mural granulosa (from having individual cells visible protruding from the surface to having full expansion with copious matrix visible between cells) were classified as expanded. Oocytes with both compact cumulus cells and compact mural granulosa were classified as compact. Only expanded oocytes were used in this study.

\section{In vitro maturation}

Selected oocytes were washed twice in maturation medium (TCM-199 with Earle's salts (Gibco), $5 \mu \mathrm{U} \mathrm{FSH} \mathrm{ml}^{-1}$ (Sioux Biochemical Inc, Sioux Center, IA), 10\% fetal bovine serum (FBS) and $25 \mu \mathrm{g}$ gentamycin $\mathrm{ml}^{-1}$ ). Oocytes were cultured in droplets at a ratio of $10 \mu \mathrm{l}$ medium per oocyte, under light white mineral oil (Sigma Chemical Co., St Louis, $\mathrm{MO}$ ) at $38.2{ }^{\circ} \mathrm{C}$ in $5 \% \mathrm{CO}_{2}$ in air for $24-26 \mathrm{~h}$. After maturation, oocytes were denuded of cumulus cells by pipetting in a solution of $0.5 \%(\mathrm{w} / \mathrm{v})$ hyaluronidase in TCM-199 with $5 \%$ FBS. Denuded oocytes were selected for the presence of a polar body. Oocytes without a polar body were fixed in buffered formal saline, mounted on a slide with $6.5 \mu$ of 9:1 glycerol:PBS containing $2.5 \mu \mathrm{g}$ Hoechst $33258 \mathrm{ml}^{-1}$, and examined using fluorescence microscopy to determine the chromatin configuration.

\section{Sperm preparation}

Fresh semen was collected from one stallion using a Missouri model artificial vagina and was then diluted to 80 $\times 10^{6}$ spermatozoa $\mathrm{ml}^{-1}$ with a commercial skimmed-milk glucose extender (Animal Reproduction Systems, Chino, CA) before further processing. Semen from the same stallion was frozen using a skimmed milk-egg yolk-based extender (Blanchand et al., 1998). Semen straws were thawed at $50^{\circ} \mathrm{C}$ for $42 \mathrm{~s}$. Two hundred $\mu$ l of semen (fresh extended or frozen-thawed) was placed in the bottom of a $5 \mathrm{ml}$ tube containing $1 \mathrm{ml}$ of modified Tyrode's albumin lactate pyruvate (TALP) (sp-TALP, Parrish et al., 1988) and incubated in an atmosphere of $5 \% \mathrm{CO}_{2}$ in air for swim-up. After $20 \mathrm{~min}$, $0.6 \mathrm{ml}$ of medium was collected from the top of the tube and centrifuged at $327 \mathrm{~g}$ for $3 \mathrm{~min}$ in a $1.7 \mathrm{ml}$ polypropylene tube. The sperm pellet was resuspended and washed once with the same medium, and the supernatant was removed and the pellet was used for ICSI.

\section{Intracytoplasmic sperm injection}

The ICSI technique was modified from the method described by Kimura and Yanagimachi (1995), using the Piezo injection system. The outside diameter of the sperm injection pipette was $7-8 \mu \mathrm{m}$. A 120-140 $\mu \mathrm{m}$ (outside diameter) pipette was used to hold the oocytes. Immediately before injection, $1 \mu \mathrm{l}$ sperm suspension was placed in $3 \mu \mathrm{l}$ sp-TALP containing 10\% (w/v) polyvinylpyrrolidone (Sigma) under oil. The injection of spermatozoa was carried out in a separate $50 \mu \mathrm{l}$ drop of Hepes-buffered TCM-199 containing $10 \%$ FBS. Each spermatozoon was immobilized by applying a few pulses with the Piezo drill (Burleigh Instruments Inc, Fishers, NY) to the sperm tail immediately before injection. All manipulations were performed at room temperature. Injected oocytes were held for $20 \mathrm{~min}$ at room temperature in the same medium to slowly heal the broken membrane, and then oocytes to be cultured in vitro were transferred into G1.2 medium (G1.2/G2.2, IVF Science, Denver, CO) and incubated at $38.2^{\circ} \mathrm{C}$ under $5 \% \mathrm{CO}_{2}$ in air. These oocytes were assessed at either 20 or $96 \mathrm{~h}$ after ICSI. Oocytes to be transferred to a recipient mare were placed in $50 \mu \mathrm{l} \mathrm{G1.2} \mathrm{medium} \mathrm{and} \mathrm{incubated} \mathrm{at} 38.2^{\circ} \mathrm{C}$ under $5 \% \mathrm{CO}_{2}$ in air until transfer $(<2 \mathrm{~h}$; see below).

\section{Preparation of bovine oocytes and ICSI}

Bovine oocytes were purchased from Ovagenix (San Angelo, TX) and were cultured overnight in a portable incubator maintained at $39^{\circ} \mathrm{C}$. Upon arrival at the laboratory, the glass tube containing the oocytes was uncapped and placed in an incubator at $5 \% \mathrm{CO}_{2}$ in air, until $24 \mathrm{~h}$ of IVM. Oocytes were then denuded by gentle pipetting in $0.05 \%$ (w/v) hyaluronidase (Sigma) in TCM-199 plus 5\% FBS. Oocytes with a first polar body were selected and used for manipulation. Sperm preparation and ICSI were performed as described above. After insemination, bovine oocytes were cultured for $20 \mathrm{~h}$ in G1.2 medium.

\section{Assessment of oocyte fertilization and activation}

At $20 \mathrm{~h}$ after ICSI, assigned equine oocytes and all bovine oocytes were fixed, stained and evaluated as described above. Oocytes in metaphase II, with either no spermatozoa visible or a condensed sperm head present, were considered to be non-activated. Oocytes in anaphase II to metaphase III (metaphase plate with two polar bodies) with individualized sperm chromosomes or a decondensing sperm head were considered to be activated but arrested in development (having incomplete activation). Oocytes with two or three pronuclei, syngamy or cleavage with the presence of nuclei in each blastomere, with one or two polar bodies, were considered to be fertilized. Three pronuclei were considered to be formed when activation of both halves of the metaphase II chromatin and decondensation of the sperm head occurred.

\section{In vitro culture}

Oocytes assigned to the $96 \mathrm{~h}$ group were cultured in their original droplet of G1.2 medium, without a change of medium. Development of embryos was evaluated each day under a dissection microscope at $\times$ 40-60 magnification, on a heated stage. At $48 \mathrm{~h}$ after ICSI, non-cleaved embryos were removed, fixed and stained to examine their fertilization status. After $96 \mathrm{~h}$ of culture, embryos were fixed and stained as described above to examine the number and 
Table 1. Pronucleus formation of equine oocytes fixed $20 \mathrm{~h}$ after intracytoplasmic sperm injection (ICSI) with two different types of equine spermatozoa

\begin{tabular}{|c|c|c|c|c|c|c|c|c|c|c|}
\hline \multirow[b]{2}{*}{ Spermatozoa } & \multirow{2}{*}{$\begin{array}{l}\text { Number } \\
\text { of oocytes } \\
\text { examined } \\
\text { (number of } \\
\text { replicates) }\end{array}$} & \multirow{2}{*}{$\begin{array}{c}\text { Number of } \\
\text { unfertilized } \\
\text { oocytes }^{\mathrm{a}}(\%)\end{array}$} & \multicolumn{3}{|c|}{$\begin{array}{l}\text { Number of incompletely } \\
\text { activated oocytes with }\end{array}$} & \multicolumn{5}{|c|}{ Number of activated oocytes with } \\
\hline & & & $\begin{array}{c}\text { Sperm } \\
\text { chromosome }^{b}\end{array}$ & $\begin{array}{l}\text { Decondensed } \\
\text { sperm head }^{c}\end{array}$ & $\begin{array}{l}\text { Total } \\
(\%)\end{array}$ & $2 \mathrm{PN}$ & $3 \mathrm{PN}$ & $\begin{array}{l}\text { First } \\
\text { mitosis }\end{array}$ & Two-cell & Total $(\%)$ \\
\hline Fresh & $41(3)$ & $4(10)$ & 4 & 4 & $8(20)$ & 24 & 1 & 1 & 3 & $29(71)$ \\
\hline Frozen-thawed & $40(3)$ & $3(8)$ & 7 & 6 & $13(33)$ & 17 & 2 & 4 & 1 & $24(60)$ \\
\hline
\end{tabular}

a Unfertilized oocytes include oocytes with an intact sperm head or no spermatozoa present.

bSperm chromosomes with oocyte in metaphase III.

'Decondensed sperm head with oocytes in pronucleus, decondensed chromosome or telophase stages.

2PN: two pronuclei with one or two polar bodies.

3PN: three pronuclei present.

status of nuclei. Only nuclei that appeared to be normal were included in the number of nuclei recorded; nuclei with signs of degeneration (vacuolization, condensation, or fragmentation) were disregarded.

\section{Oocyte transfer and recovery}

Oocytes were surgically transferred to the oviducts of recipient mares within $2 \mathrm{~h}$ of ICSI. For oocyte transfer, detomidine (Pfizer Inc., Lees Summit, MO, 3-5 mg, i.v.) and butorphanol (Fort Dodge Animal Health Co., Fort Dodge, IA, $5 \mathrm{mg}$ i.v.) were administered to the mares. Transfer of presumptive zygotes to the oviduct was performed via standing flank laparotomy, as described previously for oocyte transfer (Hinrichs et al., 1998). Oocytes that had been subjected to ICSI with fresh and frozen-thawed spermatozoa were transferred to separate oviducts. At $94 \mathrm{~h}$ after transfer, mares were killed and the uterus, ovaries and oviducts were removed. Embryos were recovered within $2 \mathrm{~h}$ by cannulating the oviductal papilla and flushing the oviduct with $50 \mathrm{ml}$ Dulbecco's PBS. Recovered embryos were evaluated under a dissection microscope, and then fixed and stained with Hoechst 33258 as described above. The uteri of the first two mares to receive transferred embryos were flushed with Dulbecco's PBS to recover any embryos that may have descended from the oviducts.

\section{Statistical analysis}

Differences among groups were evaluated using chisquared analysis. Fisher's exact test was used when the expected value for any parameter was $<5$. The numbers of embryonic nuclei were compared between treatments by the Student's $t$ test. The correlation between number of embryonic nuclei and number of oviductal nuclei present in embryos transferred in vivo was calculated by regression analysis.

\section{Results}

A total of 236 ovaries were processed, from which 1644 follicles were scraped, an average of seven follicles per ovary. Nine hundred and eighteen oocytes were recovered, of which 254 were compact, 595 were expanded and 69 were degenerating. Five hundred and forty-four expanded oocytes were used for this study, and the remainder were used on a separate project.

When the oocytes were examined after 24-26 h of maturation, seven were damaged during denuding and 537 were evaluated for presence of a polar body. Of these, 312 (58\%) had a polar body and 310 were used for ICSI. After ICSI, 301 oocytes (97\%) remained intact. Two oocytes that underwent ICSI were lost during transfer to oviducts. Of oocytes without polar bodies, 40 (18\%) were found to be in metaphase I when fixed and stained and the remainder was degenerating.

In equine presumptive zygotes fixed after $20 \mathrm{~h}$ of culture, there were no significant differences in total activation rate (complete plus incomplete) between the fresh or frozen-thawed sperm groups (90 and 93\%, respectively, Table 1). The rate of fertilization (pronucleus formation and cleavage) was 71 and $60 \%$ for oocytes injected with fresh and frozen-thawed spermatozoa, respectively. These values were not significantly different. On evaluation at $20 \mathrm{~h}$ of culture, three oocytes injected with fresh spermatozoa and one oocyte injected with frozen-thawed spermatozoa had developed to two-cell embryos. An equine oocyte with two pronuclei and two polar bodies injected with frozen-thawed spermatozoa is shown (Fig. 1a).

One hundred and sixty-two bovine oocytes were obtained, and 150 oocytes (93\%) contained a polar body after IVM and were used for ICSI. Of these, 140 oocytes (93\%) survived manipulation (ICSI or sham injection; Table 2 ). The activation rates of bovine oocytes injected with fresh or frozen-thawed equine spermatozoa were not significantly different (81 and $80 \%$, respectively). One oocyte for each treatment group had developed to a twocell embryo at $20 \mathrm{~h}$. The activation rate (pronucleus formation and cleavage) for bovine oocytes injected with frozenthawed equine spermatozoa was significantly higher than that for equine oocytes injected with frozen-thawed equine spermatozoa $(P<0.05)$, and the overall activation rate for 

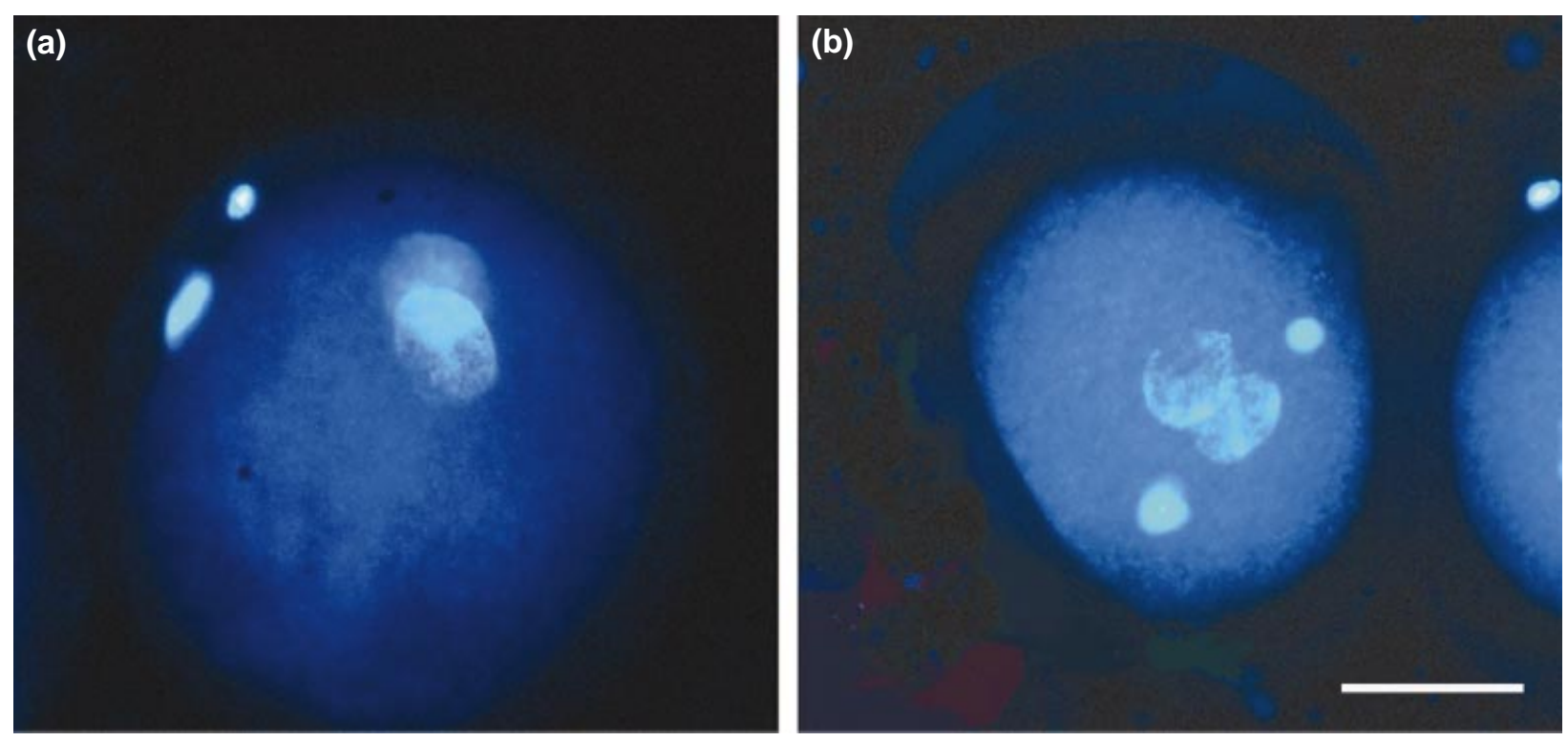

Fig. 1. Pronucleus formation after intracytoplasmic sperm injection (ICSI) in (a) equine and (b) bovine oocytes, with two pronuclei and two polar bodies visible after Hoechst 33258 staining after culture in vitro for $20 \mathrm{~h}$. Scale bar represents $50 \mu \mathrm{m}$.

Table 2. Nuclear decondensation and pronucleus formation of bovine oocytes fixed $20 \mathrm{~h}$ after intracytoplasmic sperm injection (ICSI) with two different types of equine spermatozoa

\begin{tabular}{|c|c|c|c|c|c|c|c|c|c|c|c|}
\hline \multirow[b]{2}{*}{ Spermatozoa } & \multirow{2}{*}{$\begin{array}{c}\text { Number of } \\
\text { oocytes } \\
\text { examined } \\
\text { (number of } \\
\text { replicates) }\end{array}$} & \multirow{2}{*}{$\begin{array}{l}\text { Number } \\
\text { of oocytes } \\
\text { surviving } \\
(\%)\end{array}$} & \multirow{2}{*}{$\begin{array}{c}\text { Number of } \\
\text { unfertilized } \\
\text { oocytes }^{\mathrm{a}}\end{array}$} & \multicolumn{3}{|c|}{$\begin{array}{l}\text { Number of incompletely } \\
\text { activated oocytes with }\end{array}$} & \multicolumn{5}{|c|}{ Number of activated oocytes with } \\
\hline & & & & $\begin{array}{c}\text { Sperm } \\
\text { chromosome }^{b}\end{array}$ & $\begin{array}{l}\text { Decondensed } \\
\text { sperm headc }^{c}\end{array}$ & $\begin{array}{c}\text { Total } \\
(\%)\end{array}$ & $2 \mathrm{PN}$ & $3 \mathrm{PN}$ & $\begin{array}{l}\text { First } \\
\text { mitosis }\end{array}$ & $\begin{array}{l}\text { Two- } \\
\text { cell }\end{array}$ & $\begin{array}{c}\text { Total } \\
(\%)\end{array}$ \\
\hline Fresh & $58(3)$ & $54(93)$ & $5(9)$ & 4 & 1 & $5(9)$ & 40 & 1 & 2 & 1 & $44(81)$ \\
\hline Frozen-thawed & $59(3)$ & $55(93)$ & $4(7)$ & 7 & 0 & $7(13)$ & 34 & 4 & 5 & 1 & $44(80)$ \\
\hline Sham & $33(3)$ & $31(94)$ & $31(100)$ & 0 & 0 & $0(0)$ & 0 & 0 & 0 & 0 & $0(0)$ \\
\hline
\end{tabular}

aUnfertilized oocytes include oocytes with an intact sperm head or no spermatozoa present.

bSperm chromosomes with oocyte in metaphase III.

'Decondensed sperm head with oocytes in pronucleus, decondensed chromosome or telophase stages.

2PN: two pronuclei with one or two polar bodies.

3PN: three pronuclei present.

bovine oocytes (fresh and frozen-thawed spermatozoa combined) was significantly higher than that for equine oocytes $(P<0.05)$. A bovine oocyte with two pronuclei and two polar bodies after injection with frozen-thawed equine spermatozoa is shown (Fig. 1b).

The in vitro development of equine oocytes cultured for $96 \mathrm{~h}$ after ICSI is shown (Table 3). Cleavage rates assessed morphologically were not significantly different between sperm treatments $(84 \%$ for fresh versus $76 \%$ for frozenthawed). However, the proportion of oocytes undergoing cleavage with normal nuclei tended to be higher in the oocytes injected with fresh spermatozoa than in oocytes injected with frozen-thawed spermatozoa (42 of 58 (72\%) versus 32 of 58 (55\%) for oocytes injected with frozenthawed spermatozoa), although the effect was not significant. There was no significant difference between sperm groups in the proportion of cleaved oocytes with one to seven nuclei or eight or more nuclei. Only one embryo, in the fresh sperm group, had $>16$ nuclei. The average number of nuclei was 8.6 and 7.7 for fresh and frozen-thawed sperm treatments, respectively. Three equine embryos cultured in vitro after staining with Hoechst 33258 are shown to demonstrate cell nuclei (Fig. 1b)

One hundred and two oocytes subjected to ICSI were transferred to oviducts and $68(67 \%)$ were recovered from the oviducts at $96 \mathrm{~h}$ after ICSI (Table 4). In one case at the time of transfer the oviduct appeared to have a stricture in the ampulla. Cannulation of the oviduct was attempted three times before the presumptive zygotes (oocytes injected with fresh spermatozoa) were expressed from the pipette shallowly in the ampulla. In this case, 21 oocytes were transferred and only five were recovered from the 
Table 3. In vitro development of equine oocytes fertilized by intracytoplasmic sperm injection (ICSI) and cultured for $96 \mathrm{~h}$ in G1.2 medium

\begin{tabular}{|c|c|c|c|c|c|c|c|}
\hline \multirow[b]{2}{*}{ Spermatozoa } & \multirow{2}{*}{$\begin{array}{l}\text { Number of } \\
\text { oocytes } \\
\text { examined } \\
\text { (number of } \\
\text { replicates) }\end{array}$} & \multirow{2}{*}{$\begin{array}{c}\text { Number of } \\
\text { oocytes } \\
\text { cleaved } \\
(\%)\end{array}$} & \multirow{2}{*}{$\begin{array}{c}\text { Number of } \\
\text { oocytes } \\
\text { cleaved } \\
\text { with normal } \\
\text { nuclei }(\%)\end{array}$} & \multicolumn{3}{|c|}{ Number of embryos (\%) with } & \multirow[b]{2}{*}{$\begin{array}{l}\text { Average number of } \\
\text { nuclei (mean } \pm \text { SEM) }\end{array}$} \\
\hline & & & & $\begin{array}{c}1-7 \\
\text { nuclei }\end{array}$ & $\begin{array}{c}8-16 \\
\text { nuclei }\end{array}$ & $\begin{array}{l}>16 \\
\text { nuclei }\end{array}$ & \\
\hline Fresh & $58(4)$ & $49(84)$ & $42(72)$ & $16(38)$ & $25(60)$ & $1(2)$ & $8.6 \pm 0.8$ \\
\hline Frozen-thawed & $58(4)$ & $44(76)$ & $32(55)$ & $16(50)$ & $16(50)$ & $0(0)$ & $7.7 \pm 0.8$ \\
\hline Total & $116(4)$ & $93(80)$ & $74(64)$ & $32(43)$ & $41(55)$ & $1(1)$ & $8.2 \pm 0.5$ \\
\hline
\end{tabular}
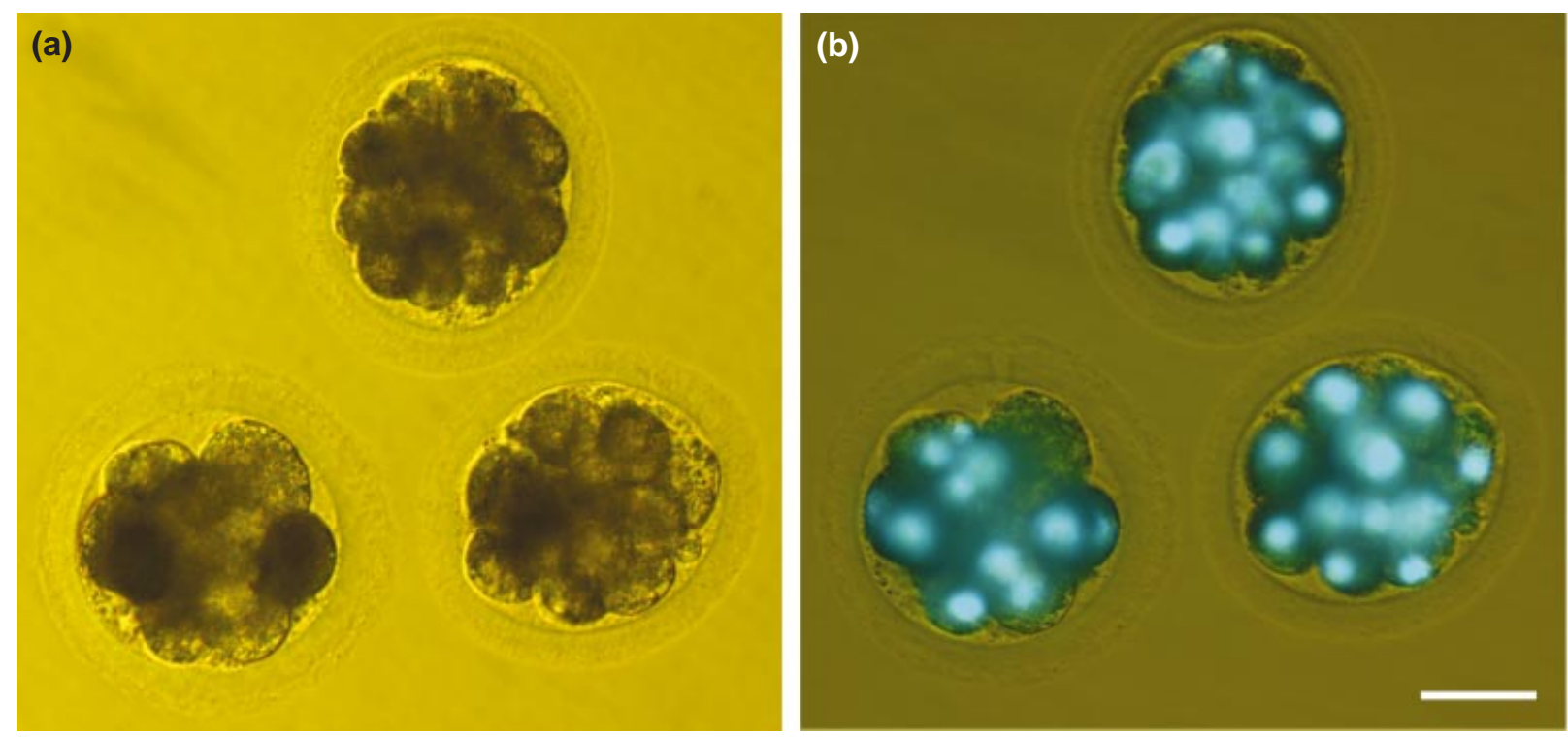

Fig. 2. Three equine embryos cultured in G1.2 medium for $96 \mathrm{~h}$ after intracytoplasmic sperm injection (ICSI) as visualized by (a) bright field and (b) fluorescence and bright field microscopy after Hoechst 33258 staining (14, 16, 23 nuclei; not all nuclei are visible). Scale bar represents $50 \mu \mathrm{m}$.

oviduct at $96 \mathrm{~h}$ after transfer. If this replicate is disregarded, of 81 transferred oocytes, 63 (78\%) were recovered. No embryos were recovered from the uterine flushings. There were no significant differences in fertilization rate, cleavage rate, proportion of embryos that had $1-7,8-16$ or $>16$ nuclei, or average number of nuclei between oocytes injected with fresh or with frozen-thawed spermatozoa (Table 4). Overall (both sperm treatments together), the proportion of oocytes undergoing cleavage with normal nuclei after oviductal transfer was similar to that for oocytes cultured in vitro (75 and 64\%, respectively). The mean number of nuclei present in the in vivo-recovered embryos was significantly higher than that for in vitro-cultured embryos (16 versus 8; $P<0.01$ ). Two embryos recovered from the oviducts after transfer and stained with Hoechst 33258 are visualized under bright field and fluorescent exposure (Fig. 3). Some embryos recovered from the oviduct appeared to be infiltrated by cells apparently of oviductal origin (Fig. 4). The numbers of potential oviductal cell nuclei visible after Hoechst 33258 staining ranged from 0 to $>100$. There was no apparent relationship between the number of oviductal cells present and the extent of embryonic development (number of embryonic nuclei; $r=0.042$ ).

\section{Discussion}

The results from the present study show that high fertilization and cleavage rates may be obtained after ICSI of equine oocytes with either fresh or frozen-thawed spermatozoa, without the use of additional activation treatment. The apparent requirement for chemical activation after ICSI as reported previously (Kato et al., 1997; Guignot et al., 1998; Li et al., 2000; Schmid et al., 2000) may be related to a lesser degree of sperm damage induced during conventional ICSI (scoring the sperm tail with the injection pipette or rolling the spermatozoa against the bottom of dish before 

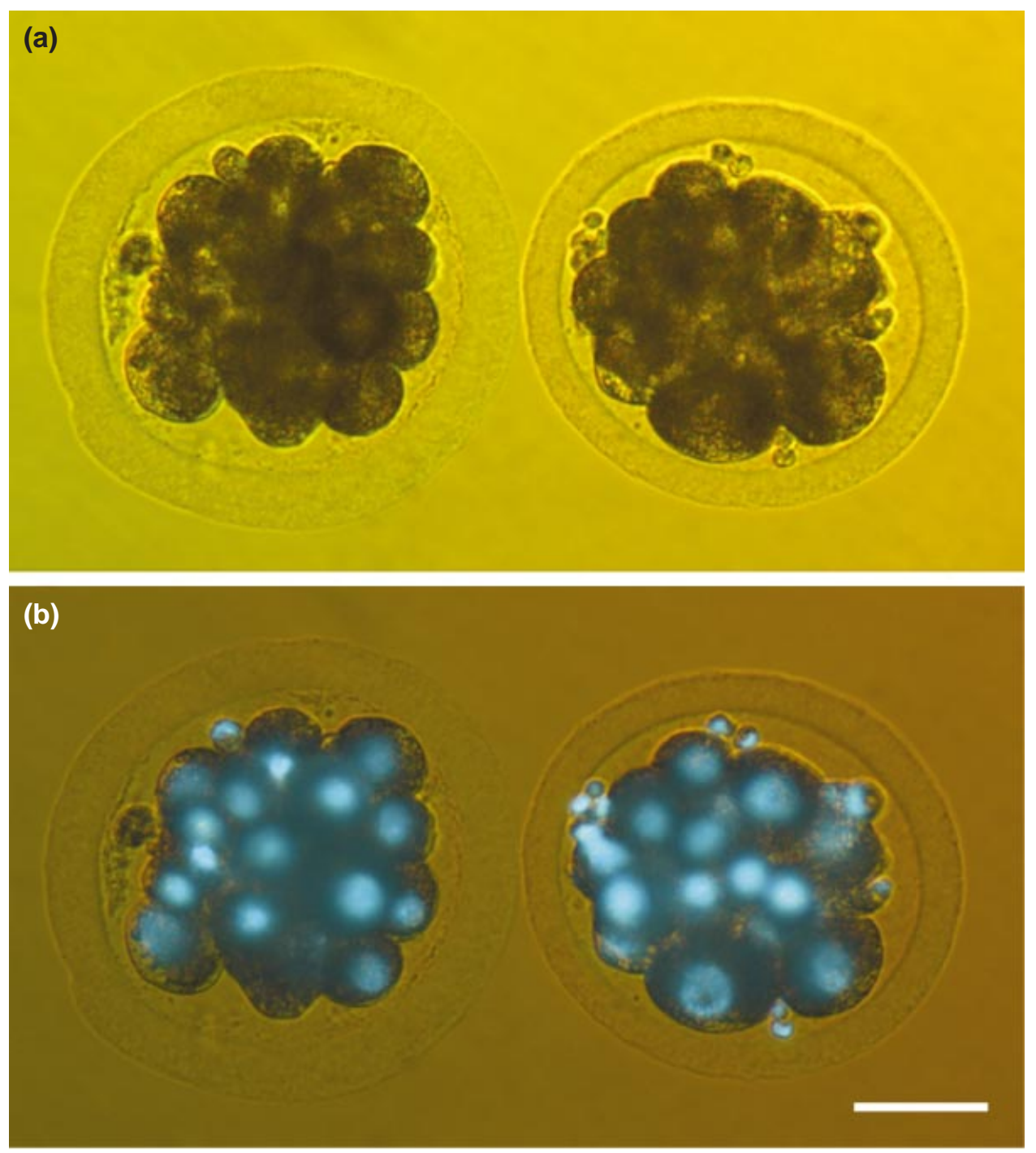

Fig. 3. Equine embryos fertilized by intracytoplasmic sperm injection (ICSI) and transferred to the oviduct for $96 \mathrm{~h}$. Two fertilized embryos both with 22 nuclei as visualized by (a) bright field and (b) fluorescence and bright field microscopy after Hoechst 33258 staining. Some nuclei are not in the plane of focus. Scale bar represents $50 \mu \mathrm{m}$.

injection; Catt and O'Neill, 1995; Dozortsev et al., 1995). Further studies comparing conventional and Piezo-driven ICSI directly are required to confirm this point.

Although the differences observed in development between equine oocytes injected with fresh or frozenthawed spermatozoa were not significant, it is notable that for every parameter measured, equine oocytes injected with fresh spermatozoa had slightly better development than those injected with frozen-thawed spermatozoa. This nonsignificant but repeatable superiority of oocytes injected with fresh spermatozoa indicates that further work in this area is warranted. In sheep, fertilization rates were higher after ICSI with fresh rather than with frozen-thawed sper- matozoa (Gomez et al., 1997). In humans, clinical pregnancy rates after ICSI with fresh epididymal or testicular spermatozoa were significantly higher than (De Croo et al., 1998) or equivalent to (Friedler et al., 1998; Janzen et al., 2000) those for frozen-thawed spermatozoa. It is important to note that the performance of fresh and frozen-thawed spermatozoa in this study may be related to either individual differences in the stallion used for the study, or the method used for freezing the spermatozoa.

Use of the Piezo drill in this study resulted in high pronucleus formation and cleavage rates. Increases in efficiency have been reported in mice, humans and cows when ICSI using the Piezo drill was compared with conventional 
Table 4. In vivo development of equine oocytes fertilized by intracytoplasmic sperm injection (ICSI) and transferred to the oviduct for $96 \mathrm{~h}$

\begin{tabular}{|c|c|c|c|c|c|c|c|c|}
\hline \multirow[b]{2}{*}{ Spermatozoa } & \multirow{2}{*}{$\begin{array}{l}\text { Number of } \\
\text { oocytes } \\
\text { transferred }\end{array}$} & \multirow{2}{*}{$\begin{array}{l}\text { Number of } \\
\text { oocytes } \\
\text { recovered } \\
(\%)\end{array}$} & \multirow{2}{*}{$\begin{array}{l}\text { Number of } \\
\text { oocytes } \\
\text { cleaved } \\
(\%)\end{array}$} & \multirow{2}{*}{$\begin{array}{c}\text { Number of } \\
\text { oocytes } \\
\text { cleaved with } \\
\text { normal } \\
\text { nuclei }(\%)\end{array}$} & \multicolumn{3}{|c|}{ Number of embryos (\%) with } & \multirow{2}{*}{$\begin{array}{c}\text { Average } \\
\text { number } \\
\text { of nuclei } \\
\text { (mean } \pm \text { SEM) }\end{array}$} \\
\hline & & & & & $\begin{array}{c}1-7 \\
\text { nuclei }\end{array}$ & $\begin{array}{c}8-16 \\
\text { nuclei }\end{array}$ & $\begin{array}{c}>16 \\
\text { nuclei }\end{array}$ & \\
\hline Fresh & 48 & $22(46)$ & $21(95)$ & $19(86)$ & $3(16)$ & $7(37)$ & $9(47)$ & $18.5 \pm 2.5$ \\
\hline Frozen-thawed & 54 & $46(85)$ & $37(80)$ & $32(70)$ & $12(38)$ & $6(19)$ & $14(44)$ & $14.4 \pm 1.8$ \\
\hline Total & 102 & $68(67)$ & $58(85)$ & $51(75)$ & $15(29)$ & $13(25)$ & $23(45)$ & $16.0 \pm 1.5$ \\
\hline
\end{tabular}

Oocytes were transferred to separate oviducts of the three recipients.

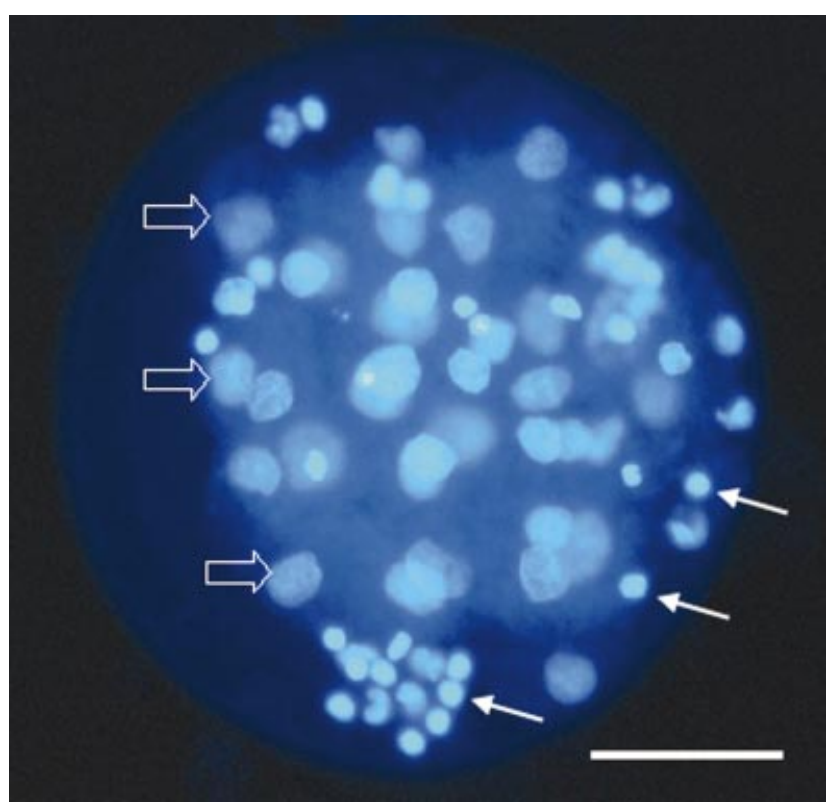

Fig. 4. Hoechst-stained equine embryo recovered from the oviduct $96 \mathrm{~h}$ after intracytoplasmic sperm injection (ICSI), showing embryonic nuclei (open arrows) and presumptive oviductal cell nuclei (arrows). Scale bar represents $50 \mu \mathrm{m}$.

ICSI (Kimura and Yanagimachi, 1995; Yanagida et al., 1998; Katayose et al., 1999). Potential reasons for higher efficiency of Piezo microinjection include both increased damage and permeabilization of the sperm membrane, as mentioned above, and more reliable breakage of the oolemma, ensuring that the spermatozoa is deposited in the cytoplasm. Although chemical activation treatment was not required after ICSI, there is a possibility that chemical activation could have a positive effect on the efficiency of ICSI. Some injected equine oocytes (20-33\%) had sperm chromosomes at metaphase or an incompletely decondensed sperm head, often with the oocyte in metaphase III. This finding indicates that initial oocyte activation (completion of meiosis) was achieved, a sign that maturationprompting factor or microtubule-associated protein (MAP) kinase activity was initially reduced, but that the activation stimulus was not maintained long enough to allow pronucleus formation. Addition of an external activation stimulus may have resulted in full activation of these oocytes.

Although scant data are available on normal development of oviductal embryos in the horse, the development in vivo seen in ICSI embryos in the present study compares favourably with that reported for in vivo-derived embryos (Betteridge et al., 1982; Peyrot et al., 1987; Bezard et al., 1989). Recovery of ICSI embryos from the oviducts of mares in vivo has been reported by Grohdahl et al. (1997) and of five oocytes recovered $48 \mathrm{~h}$ after transfer, one had cleaved. Embryonic development (including 24\% blastocyst formation) was also reported 7 days after transferring agarembedded ICSI-derived cleaved equine embryos to the oviducts of sheep (Galli et al., 2000).

The number of nuclei in ICSI presumptive zygotes cultured in vitro in the present study was significantly lower than for those transferred to the oviduct. This finding is not surprising in light of previous disappointing results on culture of in vivo-recovered equine embryos (Bezard et al., 1989; Ball et al., 1993). Blastocysts have been produced only sporadically from in vitro-derived embryos after co-coculture on Vero cell or oviductal monolayers, or trophoblast-conditioned medium (Li et al., 1995; Dell'Aquila et al., 1997b; Guignot et al., 1998; Choi et al., 1999b). Li et al. (2001) reported 30\% blastocyst development (10 of 33) when two-cell embryos, resulting from oocytes matured in co-culture, were co-cultured with cumulus cells after ICSI. Oocytes not co-cultured during maturation did not develop to blastocysts, indicating the importance of maturation conditions in embryo development after fertilization. Maturation condition (presence of follicular fluid) has also been shown to affect pronucleus formation rate after ICSI of equine oocytes (Dell'Aquila et al., 1997b).

In the present study, G1.2 medium, a low-glucose medium based on synthetic oviductal fluid (SOF; Gardner et al., 1998) was used for embryo culture. G1.2 medium is commonly used for early embryo culture in other species and is typically followed by placement of embryos in G2.2 (higher glucose) medium on day 3 or 4 of culture. Development of human and bovine embryos to the blastocyst stage in G1.2/2.2 medium can be comparable to that achieved in vivo; these media were developed after studying the 
metabolic requirements of human and bovine oocytes. No such media have been developed for culture of equine embryos on the basis of metabolic studies. The use of G1.2 medium in the present study was based on the work of Azuma et al. (1995), in which culture of equine embryos in a low glucose medium for 4 days followed by culture in a higher glucose medium resulted in an increase in the number of nuclei. Cochran et al. (1998) also found higher cleavage rates after ICSI (at $48 \mathrm{~h}$ ) when a low glucose medium (P1) was used, in comparison with M199. Li et al. (2000) used G1.2 medium for $30 \mathrm{~h}$ of culture after ICSI; however, development of equine embryos after culture for more than 30 h with G1.2 medium has not been reported.

It is difficult to compare the rate of development to the 8-16-cell stage in vitro at $96 \mathrm{~h}$ in the G1.2 medium as in the present study (53 and 35\% of cleaved embryos for fresh and frozen-thawed semen, respectively) with developmental rates reported by other workers. The reported proportion of oocytes developing beyond the two-cell stage is typically on the basis of morphological assessment of blastomeres, rather than on the number of normal nuclei present after staining. Reported rates of development of equine ICSI embryos to 8 or more cells in vitro have ranged from approximately 8\% (Gronddahl et al., 1997), approximately 19\% (Maclellan et al., 2000) and 23\% (Guignot et al., 1998), to approximately 39\% (Dell'Aquila et al., 1997b) and 25-70\% (Li et al., 2001).

Oocytes subjected to ICSI have a defect in the zona pellucida of around $8 \mu \mathrm{m}$ in diameter due to drilling with the Piezo instrument, and it has been hypothesized that after transfer this may allow maternal cellular defences to enter the embryo, resulting in embryo loss. In the present study, numerous cells were observed, apparently from the oviduct, within the perivitelline space of the embryos. With few exceptions, these cells did not appear to be polymorphonuclear. It is possible that these cells represent pyknotic or apoptotic blastomere nuclei; however, their presence in only oviductal-transferred embryos (which have better development than in vitro-matured embryos), and their large number, indicates that this is not the case. However, normal development for up to $96 \mathrm{~h}$, as estimated by number and morphology of nuclei, occurred in the presence of these cells, and there was no correlation between number of oviductal cells and extent of the embryonic development.

Bovine oocytes have been used as cytoplasts for transfer of equine nuclei, with development to the 16-cell stage (Hinrichs et al., 2000). Results from the present study indicate that bovine oocytes may be fertilized successfully with equine spermatozoa via ICSI, that is, may achieve both sperm head decondensation and oocyte activation. Thus, bovine oocytes are a possible alternative source of oocytes for research on stallion sperm nuclei transformation mechanisms, as equine oocytes are difficult to obtain in large numbers. It is notable that in many reports in cattle, sperm decondensation rates after ICSI of bovine oocytes have been low (Catt and Rhodes, 1995; Rho et al., 1998; Chung et al., 2000). Use of the Piezo drill appears to overcome the need for chemical activation in this species (Katayose et al., 1999).

In conclusion, high fertilization and cleavage rates were achieved in the present study, without chemical activation, in equine oocytes fertilized with fresh or frozen-thawed spermatozoa by ICSI using the Piezo drill. Embryo development tended to be more advanced in oocytes inseminated with fresh spermatozoa but no significant differences were noted. Oocytes transferred to the oviduct in vivo developed at a rate comparable with that reported for in vivo-derived embryos, and had significantly greater embryonic development at $96 \mathrm{~h}$ than did embryos cultured in vitro in a semidefined medium (G1.2). Bovine oocytes may serve as a model for equine oocytes in investigation of fertilization in horses.

This work was supported by the Link Equine Research Endowment Fund (Texas A\&M University) and Bio-Arts and Research Corporation.

\section{References}

Azuma T, Choi YH, Hochi S and Oguri N (1995) Effect of glucose in the culture medium on development of horse oocytes matured and microfertilized in vitro. Reproduction, Fertility and Development 7 1067-1071

Ball BA, Brinsko SP, Thomas PGA, Miller PG and Ellington JE (1993) Development to blastocysts of one- to two-cell equine embryos after coculture with uterine tubal epithelial cells American Journal of Veterinary Research 54 1139-1144

Betteridge KJ, Eaglesome MD, Mitchell D, Flood PF and Beriault R (1982) Development of horse embryos up to twenty two days after ovulation: observations on fresh specimens Journal of Anatomy 135 191-209

Bezard J (1992) In vitro fertilization in the mare Proceedings of the International Scientific Conference on Biotechnics in Horse Reproduction, Crakow, Poland Abstract 12

Bezard J, Magistrini M, Duchamp G and Palmer E (1989) Chronology of equine fertilisation and embryonic development in vivo and in vitro. Equine Veterinary Journal Supplement 8 105-110

Blanchard TL, Varner DD and Schumacher J (1998) Manual of equine reproduction. In Semen Preservation pp 143-154. Mosby-Year-Book Inc, St Louis, $\mathrm{MO}$

Catt J and $\mathbf{O}^{\prime}$ Neill C (1995) Manipulation of sperm before intracytoplasmic sperm injection improves fertilization Fertility and Sterility 64 1210-1212

Catt JW and Rhodes SL (1995) Comparative intracytoplasmic sperm injection (ICSI) in human and domestic species Reproduction, Fertility and Development 7 161-167

Choi YH, Okada Y, Hochi S, Braun J, Sato K and Oguri N (1994) In vitro fertilization rate of horse oocytes with partially removed zonae Theriogenology 42 795-802

Choi YH, Landim-Alvarenga FC, Carnevale E, Seidel GE, Jr and Squires EL (1999a) Penetration by stallion sperm of zona-free bovine oocytes matured in equine preovulatory follicular fluid Theriogenology 51316 (Abstract)

Choi YH, Chung YG, Landim-Alvarenga FC, Seidel GE, Jr and Squires EL (1999b) Development of equine oocytes matured in vitro and fertilized after partial zona removal (PZR) Biology of Reproduction Supplement 60176 (Abstract)

Chung JT, Keefer CL and Downey BR (2000) Activation of bovine oocytes following intracytoplasmic sperm injection (ICSI) Theriogenology 53 1273-1284

Cochran R, Meintjes M, Reggio B, Hylan D, Carter J, Pinto C, Paccamonti D and Godke RA (1998) Live foals produced from sperm-injected oocytes derived from pregnant mares Journal of Equine Veterinary Science 18 736-740 
De Croo I, Van Der Elst J, Everaert K, De Sutter P and Dhont M (1998) Fertilization, pregnancy and embryo implantation rates after ICSI with fresh or frozen-thawed testicular spermatozoa Human Reproduction 13 1893-1897

Dell'Aquila ME, Cho YS, Minoia P, Traina V, Fusco S, Lacalandra GM and Maritato F (1997a) Intracytoplasmic sperm injection (ICSI) versus conventional IVF on abattoir-derived and in vitro-matured equine oocytes Theriogenology 47 1139-1156

Dell'Aquila ME, Cho YS, Minoia P, Traina V, Lacalandra GM and Maritato F (1997b) Effects of follicular fluid supplementation of in-vitro maturation medium on the fertilization and development of equine oocytes after in vitro fertilization or intracytoplasmic sperm injection Human Reproduction 12 2766-2772

Dell'Aquila ME, De Felici M, Massari S, Maritato F and Minoia P (1999) Effects of fetuin on zona pellucida hardening and fertilizability of equine oocytes matured in vitro. Biology of Reproduction 61 533-540

Dominko T, Mitalipova M, Haley B, Beyhan Z, Memili E, McKusick B and First NL (1999) Bovine oocyte cytoplasm supports development of embryos produced by nuclear transfer of somatic cell nuclei from various mammalian species Biology of Reproduction 60 1496-1502

Dozortsev D, Rybouchkin A, De Sutter P and Dhont M (1995) Sperm plasma membrane damage prior to intracytoplasmic sperm injection: a necessary condition for sperm nucleus decondensation Human Reproduction $102960-2964$

Fissore RA, Gordo AC and Wu H (1998) Activation of development in mammals: is there a role for a sperm cytosolic factor? Theriogenology $\mathbf{4 9}$ 43-52

Friedler S, Raziel A, Soffer Y, Strassburger D, Komarovsky D and Roen-El R (1998) The outcome of intracytoplasmic injection of fresh and cryopreserved epididymal spermatozoa from patients with obstructive azoospermia: a comparative study Human Reproduction 13 1872-1877

Galli C, Crotti G, Duchi R, Mari G and Lazzari G (2000) Embryonic development of equine oocytes fertilised by ICSI Proceedings of the $5^{\text {th }}$ International Symposium on Equine Embryo Transfer, Saari, Finland pp 32-34 Eds T Katila and J Wade (Abstract)

Gardner DK, Schoolcraft WB, Wagley L, Schlenker T, Stevens J and Hesla J (1998) A prospective randomized trial of blastocyst culture and transfer in in vitro fertilization Human Reproduction 13 3434-3440

Gomez MC, Catt JW, Gillan L, Evans G and Maxwell WMC 1997) Effect of culture, incubation and acrosome reaction of fresh and frozen-thawed ram spermatozoa for in vitro fertilization and intracytoplasmic sperm injection Reproduction, Fertility and Development 9 665-673

Grondahl C, Hansen TH, Hossaini A, Heinze I, Greve T and Hyttel P (1997) Intracytoplasmic sperm injection of in vitro-matured equine oocytes Biology of Reproduction 57 1495-1501

Guignot F, Ottogalli M, Yvon JM and Magistrini M (1998) Preliminary observations in in vitro development of equine embryo after ICSI Reproduction, Nutrition and Development 38 653-663

Hinrichs K (1998) Production of embryos by assisted reproduction in the horse Theriogenology 49 13-21

Hinrichs K and Schmidt AL (2000) Meiotic competence in horse oocytes: interactions among chromatin configuration, follicle size, cumulus morphology and season Biology of Reproduction 62 1402-1408

Hinrichs K and Williams KA (1997) Relationships among oocyte-cumulus morphology, follicular atresia and oocyte meiotic competence in the horse Biology of Reproduction 57 377-384

Hinrichs K, Matthews GL, Freeman DA and Torello EM (1998) Oocyte transfer in mares Journal of American Veterinary Medical Association 212 982-986

Hinrichs K, Shin T, Love CC, Varner DD and Westhusin ME (2000) Comparison of bovine and equine oocytes as host cytoplasts for equine nuclear transfer Proceedings of the $5^{\text {th }}$ International Symposium on Equine Embryo Transfer, Saari, Finland pp 43-44 Eds T Katila and J Wade (Abstract)

Janzen N, Goldstein M, Schlegel PN, Palermo GD and Rosenwaks Z (2000) Use of electively cryopreserved microsurgically aspirated epididymal sperm with IVF and intracytoplasmic sperm injection for obstructive azoospermia Fertility and Sterility 74 696-701

Katayose H, Yanagida K, Shinoki T, Kawahara T, Horiuchi T and Sato A
(1999) Efficient injection of bull spermatozoa into oocytes using a piezoderiven pipette Theriogenology 52 1215-1224

Kato H, Seidel GE, Squires EL and Wilson JM (1997) Treatment of equine oocytes with A23187 after intracytoplasmic sperm injection Equine Veterinary Journal Supplement 25 51-53

Kim NH, Jun SH, Do JT, Uhm SJ, Lee HT and Chung KS (1999) Intracytoplasmic injection of porcine, bovine, mouse or human spermatozoon into porcine oocytes Molecular Reproduction and Development $5384-91$

Kimura Y and Yanagimachi R (1995) Intracytoplasmic sperm injection in the mouse Biology of Reproduction 52 709-720

Landim-Alvarenga FC, Alvarenga M, Seidel GE, Squires EL and Graham JK (2001) Penetration of zona-free hamster, bovine and equine oocytes by stallion and bull spermatozoa pretreated with equine follicular fluid dilauroylphosphatidylcholine or calcium ionophore A23187 Theriogenology 56 937-953

Li LY, Meintjes M, Graff KJ, Paul JB, Denniston RS and Godke RA (1995) In vitro fertilization and development of in vitro-matured oocytes aspirated from pregnant mares Biology of Reproduction Monograph Series 1 309-317

Li X, Morris LHA and Allen WR (2000) Effects of different activation treatments on fertilization of horse oocytes by intracytoplasmic sperm injection Journal of Reproduction and Fertility 119 253-260

Li X, Morris LHA and Allen WR (2001) Influence of co-culture during maturation on the developmental potential of equine oocytes fertilized by intracytoplasmic sperm injection (ICSI) Reproduction 121 925-932

Maclellan LJ, Sims MM and Squires EL (2000) Effect of oviductalconditioned medium during maturation on development of equine embryos following intracytoplasmic sperm injection Theriogenology $\mathbf{5 3}$ 396 (Abstract)

McKinnon AO, Lacham-Kaplan O and Trounson AO (2000) Pregnancies produced from fertile and infertile stallions by intracytoplasmic sperm injection (ICSI) of single frozen-thawed spermatozoa into in vivo matured mare oocytes Journal of Reproduction and Fertility Supplement $56513-517$

Palmer E, Bezard J, Magistrini M and Duchamp G (1991) In vitro fertilization in the horse. A retrospective study Journal of Reproduction and Fertility Supplement 44 375-384

Parrish JJ, Susko-Parrish JL, Winer MA and First NL (1988) Capacitation of bovine sperm by heparin Biology of Reproduction 38 1171-1180

Perry ACF, Wakayama T and Yanagimachi R (1999) A novel transcomplementation assay suggests full mammalian oocyte activation is coordinately initiated by multiple, submembrane sperm components Biology of Reproduction $60747-755$

Peyrot LM, Little TV, Lowe JE, Weber JA and Woods GL (1987) Autotransfer of day 4 embryos from oviduct to oviduct versus oviduct to uterus in the mare Theriogenology 28 699-708

Rho GJ, Kawarsky S, Johnson WH, Kochhar K and Betteridge KJ (1998) Sperm and oocyte treatments to improve the formation of male and female pronuclei and subsequent development following intracytoplasmic sperm injection into bovine oocytes Biology of Reproduction 59 918-924

Rybouchkin A, Dozortsev D, De Sutter P, Qian C and Dhont M (1995) Intracytoplasmic injection of human spermatozoa into mouse oocytes: a useful model to investigate the oocyte-activating capacity and the karyotype of human spermatozoa Human Reproduction 10 1130-1135

Schmid RL, Kato H, Herickhoff LA, Shenk JL, McCue PM, Chung YG and Squires EL (2000) Effects of follicular fluid or progesterone on in vitro maturation of equine oocytes before intracytoplasmic sperm injection with non-sorted and sex-sorted spermatozoa Journal of Reproduction and Fertility Supplement $\mathbf{5 6}$ 519-525

Squires EL, Wilson JM, Kato H and Blaszczyk A (1996) A pregnancy after intracytoplasmic sperm injection into equine oocytes matured in vitro. Theriogenology 45306 (Abstract)

Swan K (1990) A cytosolic sperm factor stimulates repetitive calcium increases and mimics fertilization in hamster eggs Development $\mathbf{1 1 0}$ 1295-1302

Wakayama T, Uehara T, Hayashi Y and Yanagimachi R (1997) The 
response of mouse oocytes injected with sea urchin spermatozoa Zygote 5 229-234

Wei H and Fukui Y (2000) Fertilisability of ovine, bovine or minke whale (Balaenoptera acutorostrata) spermatozoa intracytoplasmically injected into bovine oocytes Zygote 8 267-274

Yanagida K, Katayose H, Yazawa H, Kimura Y, Konnai K and Sato A (1998) The usefulness of a piezo-micromanipulator in intracytoplasmic sperm injection in humans Human Reproduction 14 448-453

Yazawa H, Yanagida K, Katayose H, Hayashi S and Sato A (2000)
Comparison of oocyte activation and $\mathrm{Ca}^{2+}$ oscillation-inducing abilities of round/elongated spermatids of mouse, hamster, rat, rabbit and human assessed by mouse oocyte activation assay Human Reproduction 12 2582-2590

Received 12 July 2001.

First decision 5 October 2001.

Accepted 7 November 2001. 